\title{
Animal Models Used in Testing the Biocompatibility of the Dental Implant - A Review
}

\author{
Diana - Larisa ANCUŢA ${ }^{1,2 *}$ Cristin COMAN $^{2}$, Diana Mihaela ALEXANDRU ${ }^{1}$, Maria CRIVINEANU $^{1}$ \\ ${ }^{1}$ Faculty of Veterinary Medicine, University of Agronomic Sciences and Veterinary Medicine, Bucharest \\ 2 "Cantacuzino" National Medical-Military Development Research Institute, Bucharest \\ *corresponding author: diana.larisa.ancuta@gmail.com
}

Bulletin UASVM Veterinary Medicine 77(2)/2020

Print ISSN 1843-5270; Electronic ISSN 1843-5378

doi:10.15835/buasvmcn-vm:2020.0020

\begin{abstract}
In order to investigate the interaction between the bone and the dental implant, in vivo testsare performed in accordance with the biocompatibility requirements. As in vitro tests do not provide sufficient data on the quality of the implants, the animal models are used because they allow a complete assessment of all the factors involved in the osseointegration process.

The aim of the paper is to provide data on the bone structure of animal species involved in dental research, highlighting the complexity of bone structure and osseointegration depending on the species. At the same time, the importance of selecting animal models is emphasized, in order to obtain the most accurate data for the development of dental implants and their use in humans. Following the research, essential data were obtained that helped to synthesize the bone characteristics of animals such as rats, rabbits, pigs, sheep or goats and relate them to the human bone skeleton. These data are useful in choosing an animal model when testing a new dental implant.
\end{abstract}

Keywords: animal model, bone, dental implant, osseointegration

\section{Introduction}

The success of applying a dental implant is influenced by factors that are dependent on both the type of device used and the individual. For several years, an attempt has been made to achieve an optimal interaction between the bone and the implant, aiming for it to be accepted by the body, to have as few adverse reactions as possible after the surgical process and to have an increased resistance to wear (Schimdt, 2001).

To verify that a dental implant is biocompatible and meets the safety requirements, it must be tested in vitro and in vivo. Cytocompatibility is the first step in assessing the toxicity of materials used in the manufacture of medical devices to characterize them in contact with bone cells. In vitro tests, moreover, are preliminary and are performed to avoid unnecessary use of animals if the materials are cytologically unsuitable. The installation of a medical device in the body of an animal is the most effective way to assess local effects on surrounding tissues, and the biocompatibility standards contained in ISO 10993-6 set out the general considerations to be taken into account when testing (ISO 109936:2016 - Part 6).

The selection of the animals that can be used for testing the dental implants is one of the most important steps, because each animal has a different bone structure. The purpose of this review is to know the details regarding the macro and microstructure of the bone for each animal species used in the research of the bone-implant interaction. 
The characteristics of dental implants that are used in the in vivo tests

Currently, there is a wide variety of dental implants, but when it comes to testing them on an animal model, one of the important factors that ought to be considered, is their size. It must be related to the size of the animal and especially their bones, so improper mounting or possible bone fractures, that would definitely result in research failure and unjustified use of animals, can be avoided. The sizes of the implants, recommended in various practical guidelines, that are used for the insertion in to the bone cortex, are closely related to the animal species. As to their integration, it is variable over time from one individual to another (Table 1), (ISO 10993-6:2016 - Part 6).
The vast majority of dental implants have a cylindrical shape, threaded, screw type, that is covered with various biomaterials. The purpose of these characteristics is to ensure an initial stability in the bone and later to favor the osseointegration (Almutairi et al., 2018).

\section{Animal Selection}

Dental medical devices, before being used in dental practice, are tested by inserting them into the animal bone. The selection of the animal species must be carefully documented and justified, taking into account the physiological peculiarities of each animal but also the similarity with the human bone (Table 2). The factors that are taken into account, when deciding on the use of a particular animal species, are those related to the availability of animals, their cost, the maintenance conditions,

Table 1. Size of dental implants / animal species and the time required for osseointegration

\begin{tabular}{lccc}
\hline \multicolumn{1}{c}{ Species } & Implant length & Implant diameter & Required time for osseointegration \\
\hline Rat & $5 \mathrm{~mm}$ & $1.6 \mathrm{~mm}$ & 12 -52 weeks \\
\hline Rabbit & $6 \mathrm{~mm}$ & $2 \mathrm{~mm}$ & 12 -104 weeks* \\
\hline Dog & $12 \mathrm{~mm}$ & $4 \mathrm{~mm}$ & 12 -104 weeks* \\
\hline Sheep / Goat & $12 \mathrm{~mm}$ & $4 \mathrm{~mm}$ & 12 -104 weeks* \\
\hline Pig & $4.5 \mathrm{~mm}$ & $2 \mathrm{~mm}$ & 12 -104 weeks* \\
\hline
\end{tabular}

*The time required for osseointegration varies depending on the material that is tested and the expected

Table 2. Similarities between human and animal bone (Bonucci et al., 2014; Chu et al., 2010; Roach et al., 2003)

\begin{tabular}{|c|c|c|c|}
\hline Species & $\begin{array}{c}\text { Macroscopic } \\
\text { similarities }\end{array}$ & Microscopic similarities & $\begin{array}{c}\text { Age of bone skeleton } \\
\text { maturation }\end{array}$ \\
\hline Human & - & $\begin{array}{l}\text { Lamellar bone with } \\
\text { extensive remodeling }\end{array}$ & $16-20$ years \\
\hline Rat & None & Primary bone throughout life & 26 weeks \\
\hline Rabbit & $\begin{array}{l}\text { Minimal } \\
\text { similarities }\end{array}$ & $\begin{array}{l}\text { Primary bone with development of secondary } \\
\text { osteons with the } \\
\text { advancement in age the development of secondary } \\
\text { osteons with age }\end{array}$ & 8-11 months \\
\hline Pig & $\begin{array}{l}\text { Moderate } \\
\text { similarities }\end{array}$ & $\begin{array}{l}\text { Plexiform bone with transition to } \\
\text { secondary osteon }\end{array}$ & $2-4$ years \\
\hline $\begin{array}{l}\text { Small } \\
\text { ruminants }\end{array}$ & $\begin{array}{l}\text { Moderate } \\
\text { similarities }\end{array}$ & $\begin{array}{l}\text { Plexiform bone up to } 7-9 \text { years of age } \\
\text { (sheep) and secondary osteon (goat) }\end{array}$ & 2 years \\
\hline Dog & Similar & $\begin{array}{l}\text { Plexiform bone with small osteon } \\
\text { remodeling }\end{array}$ & 18 months \\
\hline
\end{tabular}


their tolerance to the conditions of captivity, the existence of qualified personnel to handle the animals but also the suitability for surgery or the lifespan of the species that must be adequate to the study plan (Frisbie et al., 2006; Zoetis et al., 2003).

International Standard ISO 10993, Part 6 states that rabbits, dogs, small ruminants and pigs are used for testing the dental implants.

\section{Rats}

Even though they are not covered by ISO 10993-6, due to differences in bone structure (compared to humans), their size and limited number of devices for testing, recent studies show that this animal species is frequently used, probably due to their increased availability and of the fact that they are easy to handle and take care of. Attributes of the ideal animal model used in dental research include anatomical and physiological similarities with humans, so the rat can be used on a small scale in the dental medicine field, due to the presence of the anatomy of their incisors and relatively small areas of spongy bone (Elovic et al., 1995; Jiang et al., 2004; Lerouxel et al., 2004). When used in studies, the area of choice for the implant placement is the mandible, femur and tibia (Table 3). To reduce the number of animals that will be used, it is preferred that the insertion of the implant, be performed on both limbs.

\section{Rabbits}

In medical research rabbits are used in more than $35 \%$ of the cases. Their advantage is that they are easy to handle and have a high availability rate, also the maturity of their bone system is reached relatively fast in comparison with other species, immediately after they reach sexual maturity at the age of 6 months (Pearce et al., 2007). One of the reasons why this animal model isn't desired in the studies of oral mechanics or the osseointegration of dental implants, is the fact that the dental plaque is without roots and deeply embedded in the mandibular bone structure, which also has few areas of spongy bone. Another aspect taken into account in extensive research projects, which involve testing a large number of implants, is that no more than 6 devices can be used on the rabbit, also their size must, obviously, be adapted to the size of the animal (ISO 10993-6:2016 - Part 6). From the histological point of view, the rabbit's long bone is very different from the human one, in the sense that it has a longitudinal vascular network that includes the osteon channels, being found in the medullary canal, but also in the periosteum. Bone mineral density in the femoral or tibial cortex is lower, probably due to the poorly developed Haversian system (approx. $700 \mathrm{~g} / \mathrm{cm}^{2}$, femoral bone density and $973.6 \mathrm{~g} / \mathrm{cm} 2$ mandibular bone density). The maximum average, for the diameter of the osteon described by Martiniakova et al. (2005), was $223.79+47.69 \mu \mathrm{m}$ with a minimum average diameter of $50.79+9.71 \mu \mathrm{m}$ (Martiniakova et al., 2005). Compared to other animal models, the rabbit's skeletal system shows a rapid response (Castaneda et al., 2006) to the actions of an external stimulus, therefore, along with the prior mentioned disadvantages, the rabbit, as an animal model, isn't preferred in medical research, because it's use can interfere with the extrapolation of the final results.

\section{Pigs}

Pigs are often used for testing of dental implants due to their bone structure that resemblance in many ways the human one and the large number of devices that can be put on a single animal (Bagi et al., 2011). One of the disadvantages of the use of this animal model is their high growth rate and the difficulty in handling them caused by their reactive behavior or low stress resistance. To eliminate these inconveniences, mini-pig lines have been created, and among the most used

Table 3. Cortical and spongy bone, parameters obtained from rats by microCT analysis (Bagi et al., 2011)

\begin{tabular}{lcc}
\hline & Proximal femoral diaphysis & Mandible \\
\hline Tissue volume $\left(\mathrm{mm}^{3}\right)$ & $2.66 \pm 0.12$ & $0.97 \pm 0.06$ \\
\hline Bone volume $\left(\mathrm{mm}^{3}\right)$ & $1.01 \pm 0.03$ & $0.60 \pm 0.14$ \\
\hline Bone density $\left(\mathrm{g} / \mathrm{cm}^{2}\right)$ & $1117.6 \pm 9.5$ & $1024.3 \pm 42.5$ \\
\hline Cortical layer thickness $(\mathrm{mm})$ & $0.44 \pm 0.03$ & - \\
\hline The volume of the bone marrow & $1.64 \pm 0.12$ & - \\
\hline
\end{tabular}


in medical research are Yucatan, Lee-Sung and Göttingen (Coelho et al., 2018).

From the anatomical, morphological and the healing and remodeling capacity point of view (An and Friedman, 1999), the pig bone is similar to the human one, although, microstructurally, the trabecular network is much denser in pigs then in humans (Mosekilde et al., 1987). Similarities such as lamellar structure, density and concentration of minerals in the bone, compared to humans (Aerssens et al., 1998; Schierano et al., 2005), make the pig a good study model for the osseointegration process of dental implants, especially since their tibia is considered the equivalent of the human mandibular bone (Del Fabbro et al., 2017).

A review of miniature pigs, shows the concordance between the dental characteristics of this species and those of humans (Kantarci et al., 2015), so natural gingivitis can be observed from the age of 6 months and is manifested by gingival edema, percussion bleeding and the existence of bacterial plaque and from the age of 16 months, pigs can even develop periodontal diseases (Wang et al., 2007). This animal model is often used in experimental peri-implantitis studies where aspects such as bone resorption, gum inflammation, loss of attachment (implant) and microbiota modifications are evaluated (Hickey et al., 1991).

\section{Small ruminants (sheep / goats)}

Sheep or goats are not that used for testing the dental implants, compared to other species, although the macroscopic bone structure is close to that of humans. Histologically, the bones of small ruminants are different, the osteon has a diameter of $100 \mu \mathrm{m}$ and contains at least two central blood vessels. The age of the animal greatly influences the bone structure, the primary "embryonic" bone appears strongly vascularized and poorly organized in terms of mineralization (LopezPliego et al., 2018). After the age of 4, the sheep have a plexiform bone structure that includes lamellar bone tissue interposed with the vascular plexuses, similar to a sandwich. At 7-8 years of age, the Haversian system reshapes, becoming much more prevalent, especially in the femur and humerus (Newman et al., 1995).

Bone density and strength is much higher in small ruminants, the femoral trabecular bone being twice as dense as in humans, but there are studies that note that the density of the bone assembly differs depending on the anatomical region. In dental research, the bones of interest are represented by the femur and tibia, where several implants can be mounted because the bone remodeling and the healing potential are great. When deciding on the use of small ruminants in osseointegration studies, it should not be overlooked the fact that the bone changes during the cold season, when bone regeneration is depressed, which could influence the objectives of the experiment (Wancket, 2015).

\section{Dogs}

The use of dogs in biomedical research has recently been hit by certain ethical issues due to the fact that this species is considered a pet. Dogs are frequently used in dental studies and are a valuable model in the study of peri-implantitis due to their susceptibility to spontaneous periodontitis (Dard, 2012).

Canine and human bone have many similarities that include weight, density, organic and inorganic composition. Secondary osteon formation, epiphyseal fusion at maturity, intracortical remodeling, or bone loss in old age are other aspects of similarity to humans (Bonucci et al., 2014). The difference between human and canine bone is the speed of bone remodeling, which in dogs is higher in the trabecular component. Regarding this aspect, there are variations both depending on the anatomical region (eg lumbar vertebrae have a bone transformation rate of almost 200\% / year in young Beagle dogs) but also between individuals, the average value of the degree of bone regeneration being however about 100\% (Liebschner, 2004). The canine bone microstructure is mixed and includes secondary osteonal bone in the center of the cortex, and adjacent to the periosteum and endosteum is the plexiform bone that is formed quickly and in large quantities, providing increased mechanics and support (Wang et al., 1998; Kimmel and Jee, 1982).

In studies related to dental implants, Beagle is the accepted breed, and as an anatomical mounting region, the femur is preferred, even if many publications describe the intra-oral region, in the working method, when following the processes of osseointegration, peri-implantitis or tissue healing after experimental treatments (Vignoletti et al., 2012).

The data obtained from human research have the highest scientific value but in studies related 
to dental implants, the human model offers the disadvantage of variations such as: patient's age, health, number of the tested subjects or the need for histological evaluation of the samples. All these factors do not provide statistical relevance and make the evaluation process of a medical device difficult.

\section{Conclusions}

In dental research, animal experimentation is necessary and may provide data that cannot be extrapolated from human studies, due to the impossibility of harvesting tissues required for microscopic analysis. No species meets the ideal requirements, but an understanding of the bone differences in macroscopic, microscopic, and bone remodeling structure can direct the results of in vivo experiments.

The purpose of selecting an animal model in dental implant research, is to obtain sufficient information on the body's response to a foreign body, wound healing around implants, tissue architecture, or the mechanisms of periodontal disease.

Of the species described, the dog has the most similar bone structure to humans, which is why it is used in over $45 \%$ of studies, followed by the rabbit with a frequency of use of $35 \%$. Small ruminants and pigs, whose bones are close to human and do not have ethical inconveniences such as dogs, raise issues of availability, maintenance and handling.

As implant development and clinical use are on the rise, it is important to conduct studies to evaluate them. Animal models can provide strong support in such studies, as long as the sample is large enough to generate statistically useful data and small enough to prevent unnecessary use of animals.

Acknowledgments. This research did not receive any specific grant from funding agencies of the public, commercial, or not-for-profit sectors.

\section{References}

1. Aerssens J, Boonen S, Lowet G (1998). Interspecies differences in bone composition, density, and quality: Potential implications for in vivo bone research. Endocrinology, 139:663-670.

2. Almutairi AS, Walid MA, Alkhodary MA (2018). The effect of osseodensification and different thread designs on the dental implant primary stability. F1000Res, 7:1898.
3. An YH, Friedman RJ (1999). Animal selections in orthopaedic research. In: An YH, Friedman RJ, ed. Animal Models in Orthopaedic Research. Boca Raton, FL: CRC Press LLC:39-57.

4. Bagi MC, Berryman E, Moalli MR (2011). Comparative Bone Anatomy of Commonly Used Laboratory Animals: Implications for Drug Discovery. Comp Med, 61(1): 76-85.

5. Bonucci E, Ballanti P (2014). Osteoporosis-bone remodeling and animal models. Toxicol Pathol, 42(6): 957-969.

6. Castaneda S, Largo R, Calvo E, Rodriguez-Salvanes F, Marcos ME, Diaz-Curiel M, Herrero-Beaumont G (2006). Bone mineral measurements of subchondral and trabecular bone in healthy and osteoporotic rabbits. Skeletal Radiol, 35: 34-41.

7. Chu CR, Szczodry M, Bruno S (2010). Animal models for cartilage regeneration and repair. Tissue Eng Part B Rev, 16(1): 105-115.

8. Coelho PG, Pippenger B, Tovar N, Koopmans SJ, Plana NM, Graves DT, Engebretson S, van Beusekom HMM, Oliveira PGFP, Dard M (2018). Effect of Obesity or Metabolic Syndrome and Diabetes on Osseointegration of Dental Implants in a Miniature Swine Model: A Pilot Study. J Oral Maxillofac Surg, 76(8):1677-1687

9. Dard M (2012). Methods and interpretation of performance studies for dental implants. In: Boutrand, ed. Biocompatibility and Performance of Medical Devices. Oxford, UK: Woodhead Publishing Limited, 308-344.

10. Del Fabbro M, Taschieri S, Canciani E, Addis A, Musto F, Weinstein R, Dellavia C (2017). Osseointegration of Titanium Implants With Different Rough Surfaces: A Histologic and Histomorphometric Study in an Adult Minipig Model. Implant Dent, 26(3): 357-366.

11. Elovic RP, Hipp JA, Hayes WC (1995). Ovariectomy decreases the bone area fraction of the rat mandible. Calcif Tissue Int, 56: 305-310.

12. Frisbie DD, Cross MW, Mcllwraith CW (2006). A comparative study of articular cartilage thickness in the stifle of animal species used in human pre-clinical studies compared to articular cartilage thickness in the human knee. Vet Comp Orthop Traumatol, 19(3): 142-146.

13. Hickey JS, O'Neal RB, Scheidt MJ, Strong SL, Turgeon D, Van Dyke TE (1991). Microbiologic characterization of ligature-induced peri-implantitis in the microswine model. J Periodontol, 62: 548-553.

14. ISO 10993-6:2016. Biological evaluation of medical devices - Part 6: Tests for local effects after implantation

15. Jiang G, Matsumoto H, Yamane J, Kuboyama N, Akimoto Y, Fujii A (2004). Prevention of trabecular bone loss in the mandible of ovariectomized rats. J Oral Sci, 46:75-85.

16. Kantarci A, Hasturk H, Van Dyke TE (2015). Animal Models for Periodontal Regeneration and Peri-Implant Responses. Periodontol 2000, 68(1): 66-82.

17. Kimmel DB, Jee WS (1982). A quantitative histologic study of bone turnover in young adult beagles. Anat Rec, 203: 31-45.

18. Lerouxel E, Libouban H, Moreau MF, Basle MF, Audran M, Chappard D (2004). Mandibular bone loss in an animal 
model of male osteoporosis (orchidectomized rat): a radiographic and densitometric study. Osteoporos Int, 15: 814-819.

19. López-Pliego EM, Mora-Macías J, Giráldez-Sánchez MA Domínguez J, Reina-Romo E (2018). Histological Study of the Docking Site After Bone Transport. Temporal Evolution in a Sheep Model, 49(11): 1987-1992.

20. Martiniakova M, Omelka R, Chrenek P, Ryban L, Parkanyi V, Grosskopf B, Vondrakova M, Bauerova M (2005). Changes of femoral bone tissue microstructure in transgenic rabbits. Folia Biol (Praha), 51: 140-144.

21. Mosekilde L, Kragstrup J, Richards A (1987). Compressive strength, ash weight, and volume of vertebral trabecular bone in experimental fluorosis in pigs. Calcif Tissue Int, 40: 318-322.

22. Newman E, Turner AS, Wark JD (1995). The potential of sheep for the study of osteopenia: current status and comparison with other animal models. Bone, 16: 277S-284S.

23. Pearce AI, Richards RG, Milz S, Schneider E, Pearce SG (2007). Animal Models for Implant Biomaterial Research in Bone: A Review. Eur Cell Mater, 13: 1-10.

24. Roach HI, Mehta G, Oreffo RO (2003). Temporal analysis of rat growth plates: cessation of growth with age despite presence of a physis. J Histochem Cytochem, 51(3): 373383.
25. Schierano G, Canuto RA, Navone R (2005). Biological factors involved in the osseointegration of oral titanium implants with different surfaces: A pilot study in minipigs. J Periodontol, 76: 1710-1720.

26. Schmidt C, Ignatius AA, Claes LE (2001) Proliferation and differentiation parameters of human osteoblasts on titanium and steel surfaces. J Biomed Mater Res 54: 209215.

27. Vignoletti F, Abrahamsson I (2012). Quality of Reporting of Experimental Research in Implant Dentistry. Critical Aspects in Design, Outcome Assessment and Model Validation. J Clin Periodontol, 39 (Suppl) 12: 6-27.

28. Wancket LM (2015). Animal Models for Evaluation of Bone Implants and Devices: Comparative Bone Structure and Common Model Uses. Vet Pathol, 52(5): 842-50.

29. Wang S, Liu Y, Fang D, Shi S (2007). The miniature pig: a useful large animal model for dental and orofacial research. Oral Dis, 13: 530-537.

30. Wang X, Mabrey JD, Agrawal CM (1998). An interspecies comparison of bone fracture properties. Biomed Mater Eng, 8(1): 1-9.

31. Zoetis T, Tassinari MS, Bagi C (2003). Species comparison of postnatal bone growth and development. Birth Defects Res B Dev Reprod Toxicol, 68(2): 86-110. 